\title{
TIME DISTORTION IN NUCLEAR WAR
}

M. R. Gustavson

April 10, 1974

Prepared for U.S. Atomic Energy Commissian under contract No. W-7405-Eng 48

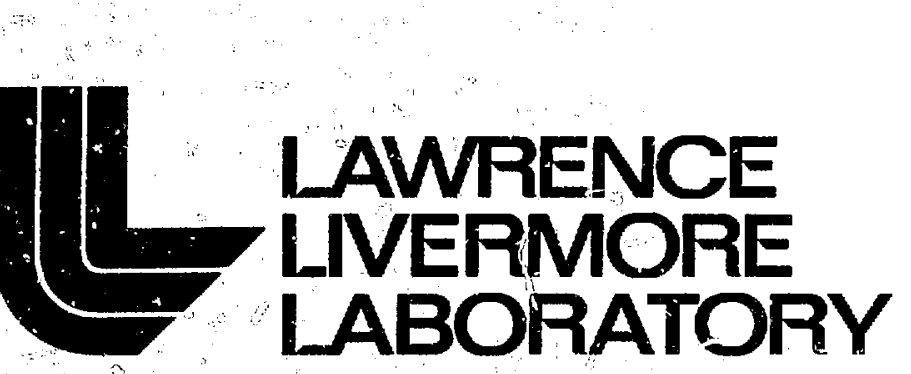

University of Calfomia/Livermore 

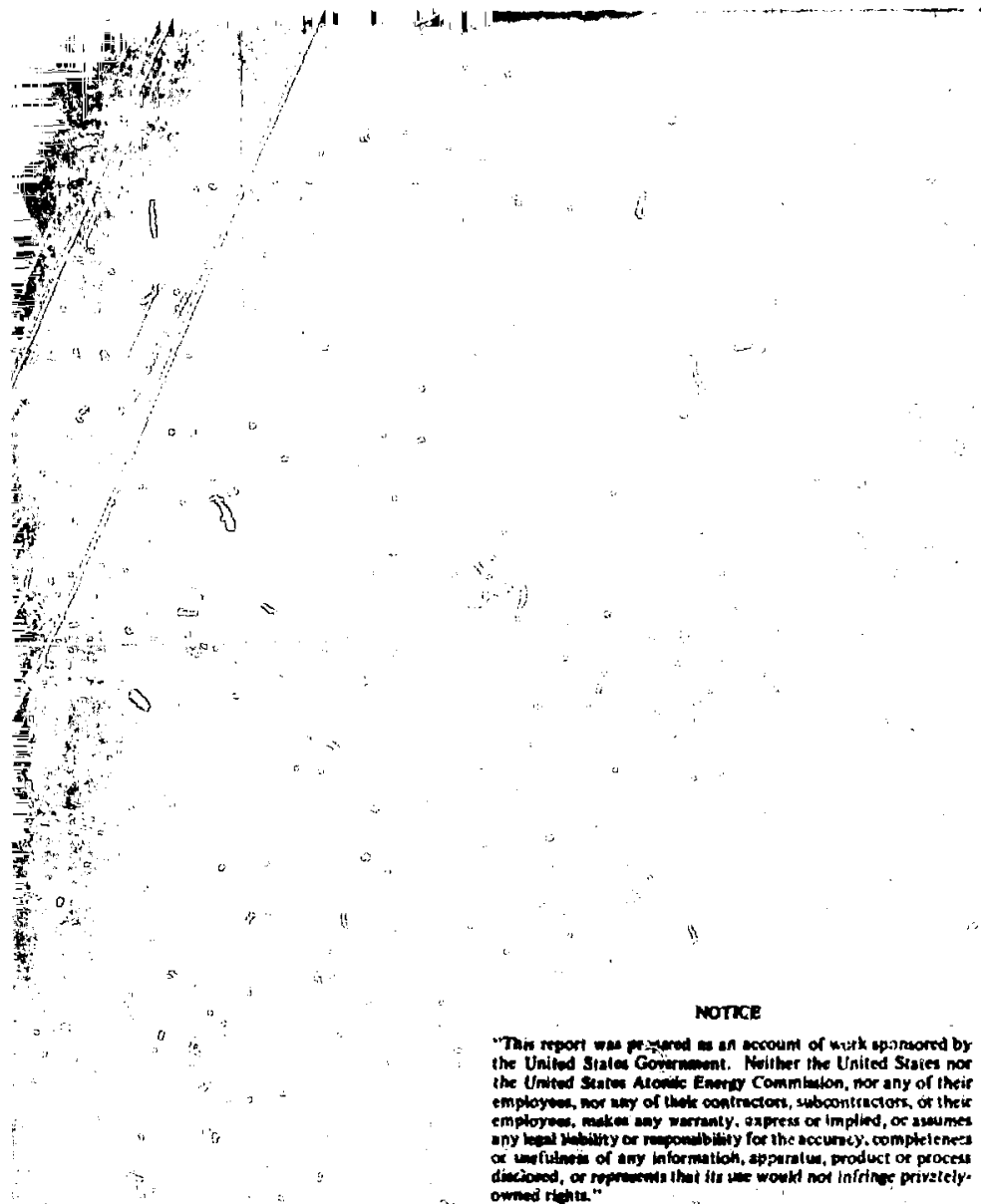

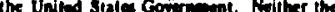

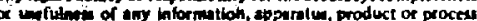

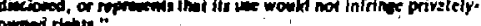

Printed in the United States of America Available from

National Technical Information Service

U.S. Department of Cómmerce 5285 Port Royal Road

Springfield, Virginia 22151

Price: Printed Copy $\$$ *; Microfiche $\$ 0.95$

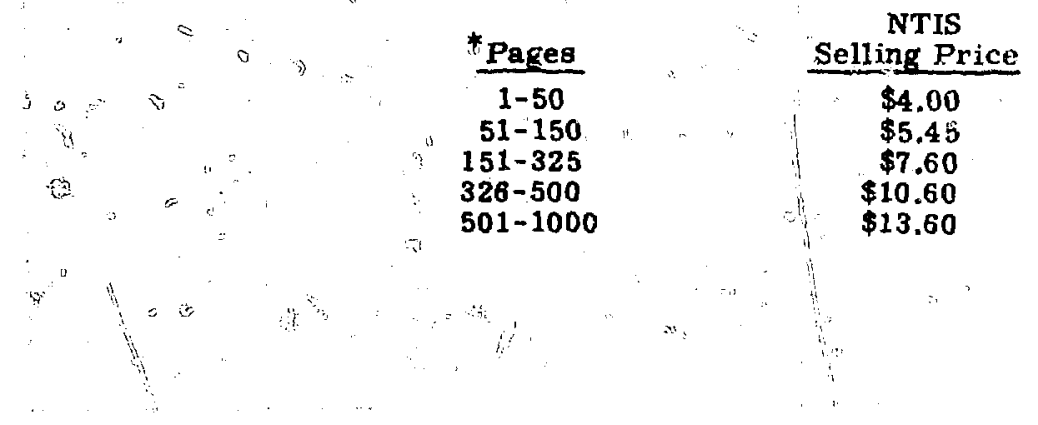


TID-4500, UC-2

Gineral, Miscellaneous, and

Progress Reports

\title{
近 \\ LAWRENCE LNEFWOPE LAEORATOFY

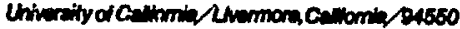

JCRL-51572

\section{TIME DISTORTION IN NUCLEAR WAR}

\author{
M. R. Gustayson
}

MS date: Apr!! 10, 1974

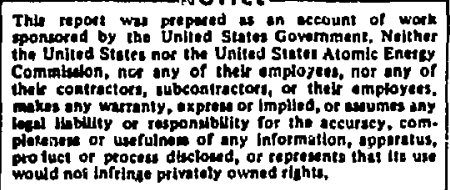

would noi infininge privateiy owned plghts.

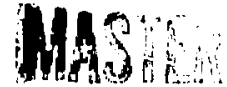




\section{Abstract}

Past sonsiderations of nuclear war, partisularly those involving battlefield use, lsave not taken into account is major factor: the time-dependent nature of the human body's response to radiation. This factor is likely to introduce changes in the temporal nature of warfare as profound as the spatial changes associuted with the increased explosive power of nuclear munitions. High fatality rates will last for days following a nuclear event and must be taken into account. Continued lack of attention to this aspect of nuclear warfare is likely to result in inappropriate choices of military posture, doctrine, and equipment.

\section{General Discussion}

Today increasing attention is devoted to concepts involving the tactical or battlefield use of nuclear weap. ons. Compared to similar studies of nonnuclear war, the key inpui parameter changed in such studies is explosive power. Account is thus tsken of the much greater radius of destruction that can be achieved by a warhead of given weight using nuclear rather than chemical explosives. This change nlone gives nuclear studies a much diffierent character from those involv. ing solely nonnuclear (oi conventional) weapons. For example, massing of forces is tenerally uneful for penetration when solely conventional firos are considered; this practice may creale extremely attractive targets for nuclear fires.

Somewhat swed by the nature of the changes thus implied, scientists have tended to look ro furtherto try only to cope with this vastly increased explosive power. This approach turns out to be quile diff?cult. Yet, since no one has experience with tactical biuclear war, it would not be surprising to discover that there are other nuclear battlefield effects of equal or larger significance. If so, many current studies of tec. tical nuclear war may be incorrect or misteading in the outcomes they predict. This in turm sould iead to an incorrect posture, foctrine, and cheice of equipment. It could even result in an inappropriate responso to enemy threats and to lessened militury effextivenes should the need ever arise for the United Siates to use nuclear weapons on the battlefield.

With these consideralions in mind, it is intereating to note how common it has been to picture nuclear bettes as if they would start and slop with a temporal tharpness amalosous to nonsadelear battles. The earli. ett scenurios of massive nuclear stntegis exchange were couched in terme of atrike, followed by survivon cotaliating, followed by both sides procending to fur- ther actions. Implicil was a notion that with the strike over the damage was done. Later, more sophistlcated studies included such effects as fallout. However, even in these studies a clear distinction was usually made between "prompt" fatalitice and those deaths occurrtin much later because of the "lingering" effects of radioactive debris.

More recently a concept of incisive but linited nuclear strikes of short duration (a fow hours) has received much disecussion. In such discussions the effects produced are frequently assumed to be coincident with, or at least promptly following, the oxecution of the nuclear strike as is usual with conventional ordnance. Numerous gaming studles involving nuclear war have now been completed. In many cases the win/ defeat criteris or hostilities cut-off has been set by a calculation of prompt fatelities. This may be appropriate for battles involving nonnuclear weapons, but is it vaild when nuclear fires are involved?

There are many ressons for believing that the tem. poral impact of effects of uaing nuclear ordnance on the buttlefteld will in practice be quite different from those associated witt: nonnuclear ordnance. There are, most obviously, the time factors noted above associated with the defosition of residual radioactivity by fallout or precipitation scavenging and the time re. quired after deposition for significant doses to be accumulated. These are difficult effects to quantify and ones which may be greatly reduced by the ayoidance of groun: bursts or through weapon desjen. It may also be true that leadership decisions will be made slowly or haltingly since battlefield nuclear warfare will ba totally new experience. This is nearly imposalble to quantify. Certainly, however, to assume a lack of speed and determination by an enemy is not a sound basis for millitary planning. Finaliy, where nu. clear weapons are used for deep interdiction, their military utility will only fully be ascessible as the $\mathrm{im}$. pact on engajed forces occurs.

This pnper proposes, however, that even if all of these facton do influence the temporal nature of nuclear wat, they do not include the most important factor. That factor is the time dependent mature of the human body's cesponse to a dose of radiation; that response will result in continuing falalities over lons perfods followilis a nuclear explosion. Looked at from the fatalities viewpoint, nuclear enpagements will perforce tend to be lone-drawn-out affaizs lesting for days.

Not only will the spatial character of nuclear wat bu different from that of conventional war, the tenjpo. ral nuture will be different in en at least as significant a way. To demonserate and illustratis this situalion, a specific case has been worked out in come detail. The 
nexi section of this paper dexcribes a model situation evaluated and the data used in the calculations. The following section explains the calculation and presents the results. The final section sugests certitin consequences that may be derived from this observation about nuclear warfare.

\section{Model and Data}

The specific situation evaluated by this paper in. volves the air burst of a one-kiloron. alt-fission, nuclear weapon over a uniformly populated plain. It focuses on radiation as the primary kill-mechanism because in this case, as for all air-burst nuclear wespons of liss than several tens-of-kilotons yield, radiation vill be the kill-mechanism with the largest lethal radjus against exposed personnel. The calculaticn is done in terms of percentage of total fatalities and, as will be shown. the results are valid for any uniform density. In fact, it will be seen that the most interesting resulis have a general validity not greatly dependent on the defalls of the calculation molel.

Calculation of fatalities as a function of time in. volves the following quantities:

$$
\begin{aligned}
& D(R)=\text { radiation dose at rairge. } R \\
& P_{k}(D) \text {. = probability of ultimate death given } \\
& \text { dose, D } \\
& T_{k}(D)=\text { time-10-deatli given dose, } D \text {, for those } \\
& \text { killed } \\
& \mathbf{N}=\text { population densily (per unit area) } \\
& F(t)=\text { iotal fatalities up to time, t. after } \\
& \text { exposure }
\end{aligned}
$$

Noting the radially symmetric sature of the exposure field, the tntal number of fatalities occurring up to time $t, F(t)$, is expressed by:

$$
\begin{aligned}
F(t) & =\int_{0}^{R_{t}} 2 \pi R \cdot N \cdot P x(D) d R \\
& =2 \pi N \int_{0}^{R_{t}} R \cdot P x\{D(R)\} d R,
\end{aligned}
$$

where $R_{t}$ is implicitly defined by:

$$
\left.t=\operatorname{Tx}(D)=\operatorname{Tk}\left\{D_{1} R_{1}\right)\right\}
$$

The fraction of the total ultimate fatalities occuring by time, $t$, is expressed by:

$$
\frac{F(1)}{F(1=\infty)}=\frac{\int_{0}^{R_{1}} R \cdot P_{K}\{D(R)\} d R}{\int_{0}^{\infty} R \cdot P_{k}\{D(R)\} d R}
$$

As noied earlier, this ratio is independent of the population densily, $\mathbf{N}$.

It is also of interest to calculate the averuge time. todeath from $t=$ of those who stirvive for some time. $\tau$. after exposure, but ultimately die as a direct result of the radiation exposure. This quantity. written as $\bar{T}(\tau)$, is expressed by:

$T(*)=\frac{\int_{R_{T}}^{\infty} R \cdot P_{K}\{D(R)\} \cdot T_{K}\{D(R)\} d R}{\int_{R_{T}}^{\infty} R \cdot P_{K}\{D(R)\} d R}$

Evaluation of this quantity permits improved understanding of the characteristic time periods for deiayed fatalitius-that is, after the early deaths have accurnd.

Evalidation of $F(t) / F(t=\infty)$ or $T(r)$ reguires a knowledge of three relationships: $D(R), P_{x}(D)$, and $T_{i i}(\mathrm{D})$.

The first of these relationships is well known. The case calculated here uses the dose vs. range given in Figure 11.91 of the 1962 Edition of The Effects of Nuclear Weapons. This gives totul rems vs. slant range for a one kiloton (fission) weapon air burst. For the ranges of in:portance herein the slant range can be used as ranie from ground zero with negligible impreciston. At the acute radiation effects levels-of-inter'st (death), there is a unit relationship between rems and rads (p. $\therefore 80$, same reference). The data used are shown in Figur: $I$ and tabulated below.

\begin{tabular}{cc} 
Dose (Rads) & Range (Yards) \\
\cline { 2 - 2 } 10000 & 445 \\
5000 & 530 \\
2000 & 650 \\
1000 & 750 \\
500 & 875 \\
200 & 1000 \\
100 & 1200
\end{tabular}

As has been widely noted, available dati at fatal dose levels for man are spare; most of the data quoted are derived from nonhuman exposures. Furthermore, none of these data takes precisely into eccount differences in levels of healtl or nutrition, extent of medical care, or other possibly significant factors. Fortunately, the general insight sought in this paper does not require precise knowledge of the relationships 


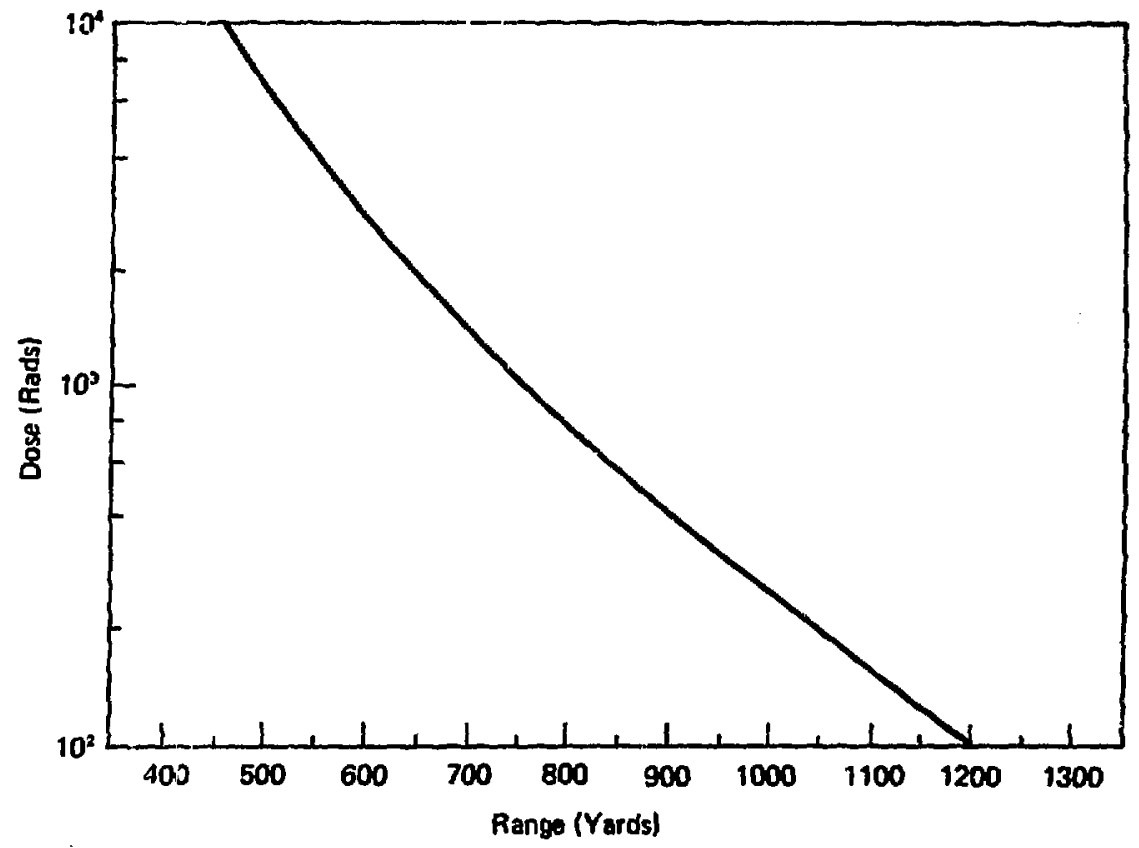

Fig. 1. Dose va. Range for I Kiloton (Fision) Alrburst

PX(D) and TK(D). Various sources have been corr. pared to derive the data used below with special re. lience placed on Table 11.111 of The Effecis of Nit. ciear Weapons and Table 10.2 of Defouse Nuclear Agency Effects Manual Number i.

The relationsinip between percentage of fatalities and whole body dose was corstructed using the fol. lowing data points.

\begin{tabular}{cc} 
Dose (Rads) & \% Fatalltles \\
\cline { 2 - 2 } 600 & 90 \\
450 & 50 \\
400 & 30 \\
200 & 1
\end{tabular}

As seen in Figure 2, when these points are plotted on probability paper, a straight line resslts. It is not clear to the author that this is entirely fortuitoix.

Time-to-death data for those who die from whole body radiation expcsure are even more sparse; orly ranges can be astabijshed. Again using the references noted above, the values tabulated above represent best estimates:

\section{Dose (Rads) Time-10-Death (Hours)}

$\begin{array}{rr}5000 & 10 \cdot 25 \\ 1000 & 150 \cdot 350 \\ 600 & 300 \cdot 1000 \\ 400 & 500 \cdot 2000\end{array}$

These data are plotted in Figure 3 along with a solid line described by the equition: $T_{k}=2.5 \times 10^{7} \mathrm{D}^{5 / 3}$, where $T x$ is the time-10-desth in hours and $D$ is the dose in rads. This line appeais to fit the available data adequalely. No theoretizal reason is apparent for this formulation and. therefore, it stould not be applied outside the range of 200 to 10,000 rads.

\section{Calculations and Resules}

Figures 1, 2, and 3 provide the relationships nec. essary for computation. The easiest procedure is to integrate numesically the numerator and denominator of equation ( $J$ ) to obtain values of $F(t) / F$ $(t=\infty)$ for vatious values of $t$. This is the procedure used to obtain the values tabulated above for the fraction of total ultimate fatalities which occur by time, $t$. 


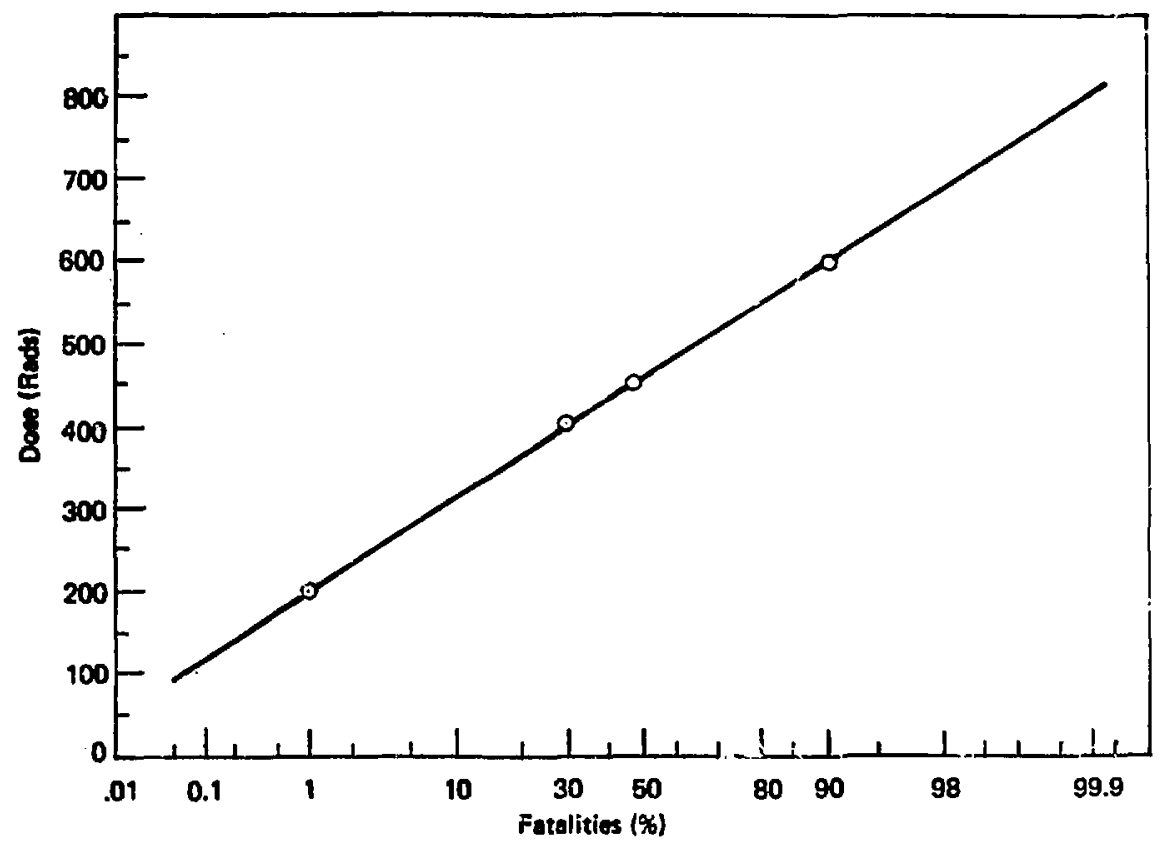

Fit. 2. Dose n. Fatulities

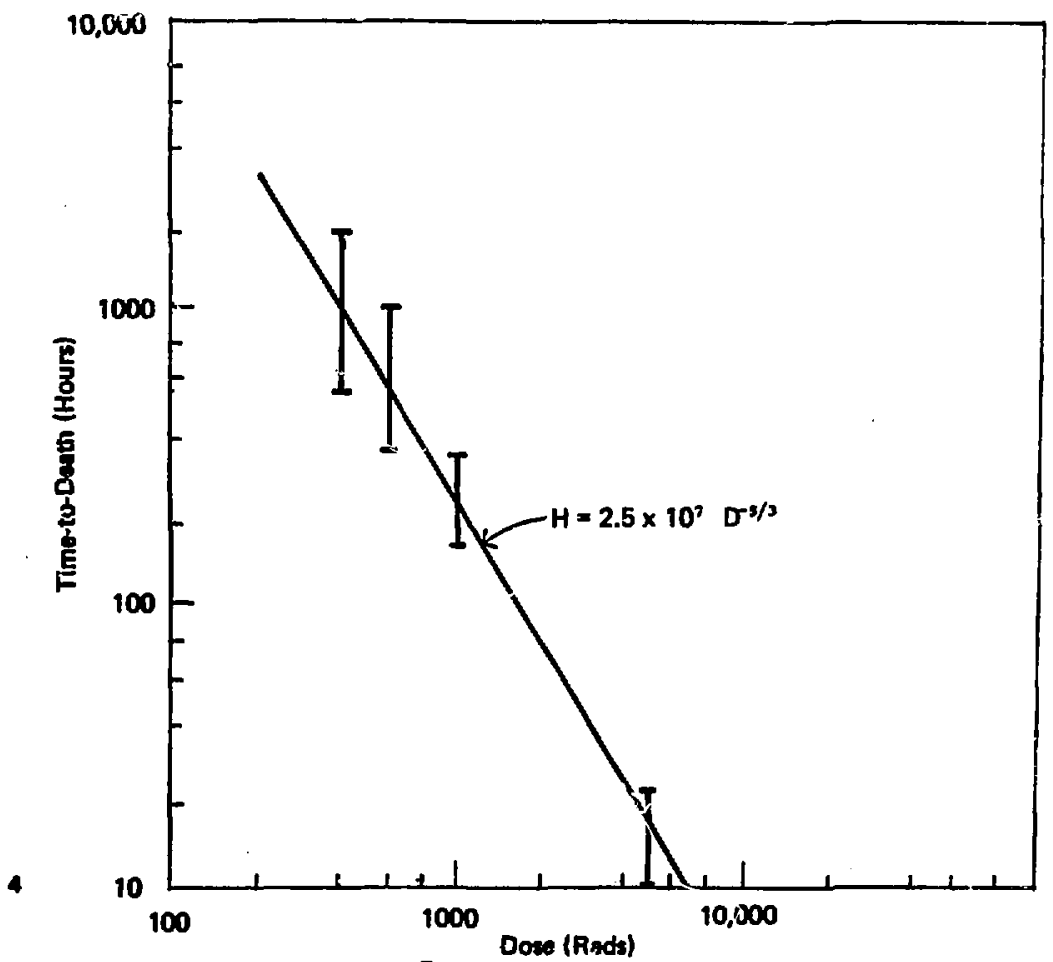

Fis. 3. Timo-to-Desth ve Done 


\begin{tabular}{|c|c|c|c|c|c|c|}
\hline$t$, hours & 10 & 20 & 40 & 60 & 80 & 100 \\
\hline$F(t) / F(t=\infty)$ & 0.33 & 0.39 & 0.47 & 0.52 & 0.56 & 0.59 \\
\hline
\end{tabular}

\begin{tabular}{|c|c|c|c|c|c|c|}
\hline$t$, hours & $i 00$ & 200 & 400 & 600 & 800 & 1000 \\
\hline$F(t) / F(t=\infty)$ & 0.59 & 0.71 & 0.83 & 0.92 & 0.96 & 0.98 \\
\hline
\end{tabular}

Figures 4 and 5 show $F(t) / F(t=\infty)$ as a function of time using both logarithmic and linear time scales.

Values of $\mathrm{T}(\tau)$, the average time-to-death from $\mathrm{t}=0$ of those who survive for some time $\tau$ after the explosion, have also been computed using equation (2). Note that the average survival time is measured from the time of the explosion of exposure but only those who survive beyond time $t$ yet ultimately die from the radiation exposure are included in the averuge:* thus $\overline{\mathrm{T}}(\tau)>\tau$.

\begin{tabular}{|c|c|c|c|c|c|c|}
\hline$\therefore$, hours & 0 & 10 & 50 & 100 & 500 & 1000 \\
\hline $\bar{T}(\tau)$, hours & 235 & 300 & 390 & 460 & 800 & 1300 \\
\hline
\end{tabular}

Examination of these results leads to a number of specific observations.

- Total deaths at early times is likely to be a misle, iding indicator of ultimate fatalities. For example, after 10 hours only abuut one-third of those who will ultimately die will actually be dead. In fact, because of the biological processes involved, many of those who ultimately will die will "feel" much better than they did during the first hours after exposure.

- Reporis from the exposure zose will be especially easy to misread. In the region around $\mathbf{8 0 0}$ yards from ground zero, twenty-four hour teports will indicate $<1 \%$ fatalities. However, $>99 \%$ of the people in that region will die with most of the fatalities occurring more than two weeks later.

- The effects in terms of fatalities will be relatively long term. Half of the deaths will occur more than two days after exposure.
- For those who do dic from radiation c posure. the average time of survival will be a $a$ rptisingly long $\mathbf{2 3 5}$ hours-almost ten days.

- The median lifetime and average lifetune differ greatly: $\mathbf{S 0}$ hours versus $\mathbf{2 3 5}$ hours. At $\mathbf{5 0}$ hours. when half the total number of fatalities have oc. curred, the average additional lifetime for those remaining will be 240 hours-more than 2 weeks.

-This is analogous to evaluating for a population group the average age at death for those who surive to some minimum age. Early deaths (infant mortality for example) can thus be removed from the averaging for age-at-desth. Clear:y, the average age-at-death for those that live for at least. say, 20 years must be greater than 20. 


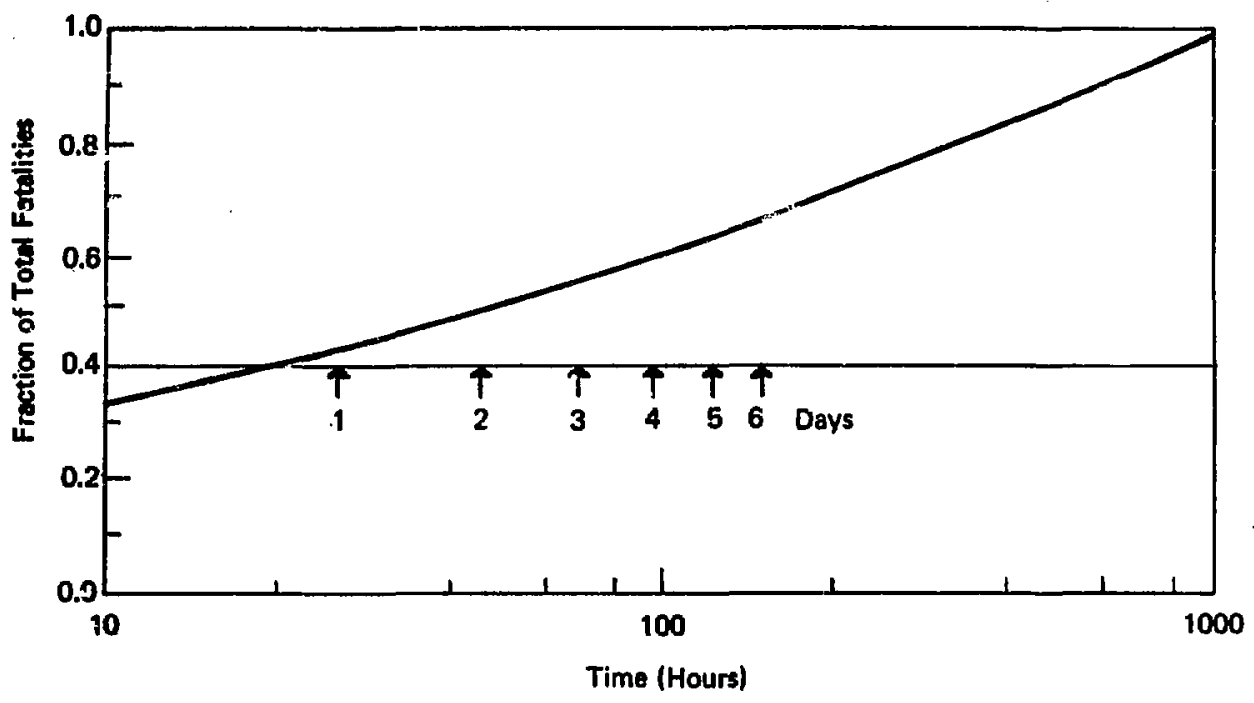

Fig. 4. Fraction of Total Fatalities ve. Time

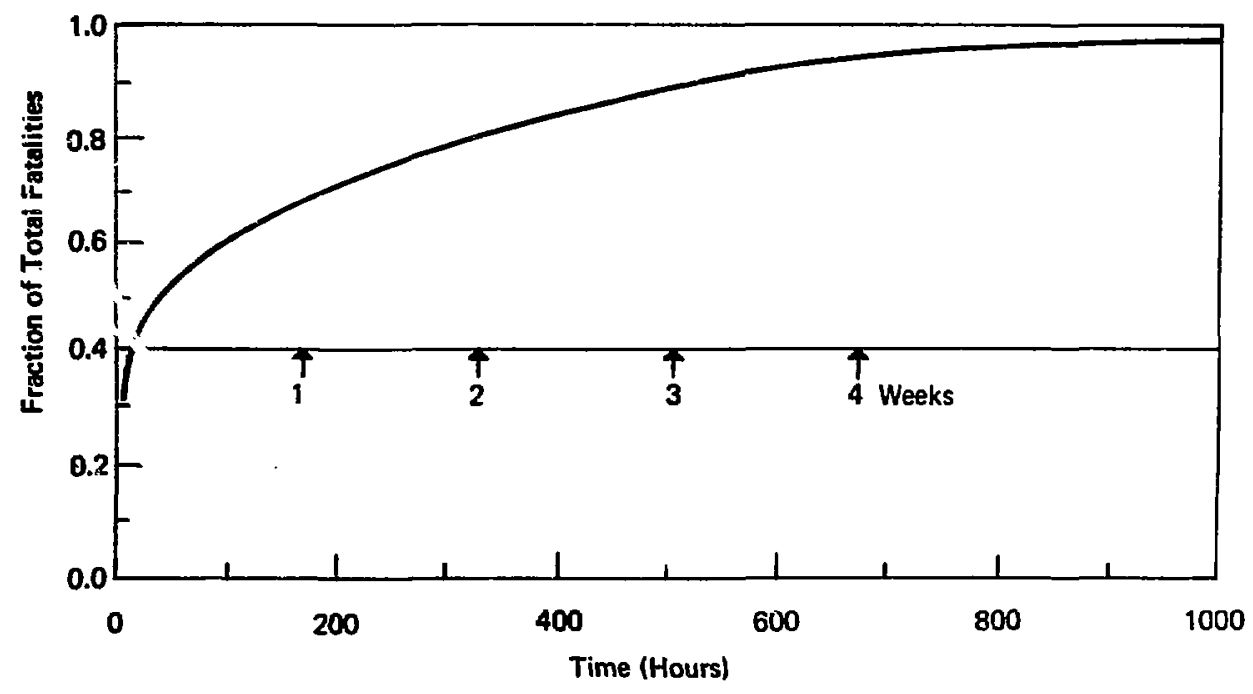

Fig. 5. Fraction of Tutal Fatalities vs. Time 
Wiile these observations are only valid in detail for the case calculated, their general implications will most likely pr: ve valid over a range of conditions. In particular, they are unlikely to be much altered by changes in yield of a few fold, by shielding, or by deriving part of the explosive yield from fusion rather than fission. While detailer calculations for a wide varjety of situations using !he best available data are certainly worthwhile, the general conclusion will not be significantly affected; that the deaths from nuclear weapons having low-to-moderate yields will occur over many days following the explosion.

\section{Consequences}

The observation that the radiation deaths from nuclear weapons having less than several tens-ofkilotons yield will take place over a period of days has a nurnber of interesting and important consequences. Discussion of a few of these will clarify the significance of this aspect of nuclear war. This discussion also suggests some areas that merit additional study.

Perhaps clearest is the fact that on the nuclear battlefield there will be a new class of personnel: those who, while rot incapacitated, have received doses of radiation which will ultimately prove lethal. The nature of the effect of large (hundreds of Rads; instantaneous radiation doses on the human body is that an initial period of depressed capability is followed by a period of recovery. The time to recover is often less than one hour. There then follows a period which may last for many days during which the exposed personnel can perform substantially as well as they could prior to exposure. This period is ended by an accelerating decline in capabilities and, in some cases, death. For example, at the $800 \mathrm{rad}$ level the post-exposure period of substantial capability is on the average about ten days to two reeks, but only one in one thousand will ultimately survive. Whether considered in terms of military (or nonmilitary) personnel or objectives, this constitutes a most unusual popula. tion group.

It is questionable that members of this group can be identified or that individuals will know the levels of their own exposures. Even if one sets aside psychological factors and considers only military personnel, the options available and appropriate command actions are not clenr. Furthermors, there could he considerable disparity between Pact and NATO views on such an issue as well as important differences be. tween the actions appropriate for an attacker as op. posed to a defender.

Some of the most interesting and difficult problems suggested by this paper arise when concrete application is made to limited use situitions. Consider. for exam. ple. the problem of using a limiled number of suclear weapons to counter a massed enemy attack. The defenders resort to nuclear weapons to reduce the unfavorable force ratio caused by eneny massing. But the defender might also decide that to do much more than restore the status quo ante of approximate force equivalence would lead to escalation by the attacker rather than to war termination. However, as has been illustrated, the use of nuclear weapons introduces a transient which lasts many days. Thus, if the defender uses a set of strikes of sufficient nuclear firepower to regain force balance within a few hours, he is likely to have created a situation in which the attacker sees hinself being put at grave risk a few days later when all of the resulting fatalities have occurred. But for the defender to use much less force denies him the ability to stop or resist the immediate attack.

Such considerations lead to a perception of how much the introduction of nuclear weapons may clange the way in which time must ba considered on the battlefie"d. Once the attacker's forces have been exposed to radiation, delay muy result in reduced available forces even though the defender takes no further action. Or the defender, once subjected to nuclear firs, may find his position deteriorating even though the attacker has taken no further action. The whole notion of reserves can be given a different meaning: namely. those who have not been exposed to significant radiation. Mobility could become important in the unusual sense of being able to usefully shift troops having limited life expectations.

The nature and scope of this limited set of possible consequences call attention to a number of important matters. If an understanding of the doctrine, posture, and equipment appropriate for nuclear war is to be achieved, the full spectrum of the changes resulting from the introduction of nuclear weapons must be considered. Certainly the impact on time, as well as on space, resulting from the introduction of nuclenr weapons must be comprehended. 